\title{
Influence of Confinement Pressure on the Development of Three Stage Curve for Bituminous Mixtures
}

\author{
V. G. Gayathri ${ }^{1}$ Yoga Priyadharshini Rajasekar ${ }^{1} \cdot$ K. Lakshmi Roja ${ }^{1}$ • \\ J. Murali Krishnan ${ }^{1}$ (D)
}

Received: 17 September 2015/ Accepted: 20 April 2016/Published online: 24 May 2016

(C) Springer International Publishing Switzerland 2016

\begin{abstract}
As part of the mechanistic-empirical pavement design procedure, the flow number test is used to rank the bituminous mixtures for rutting. In the flow number test, a sample is subjected to $0.1 \mathrm{~s}$ of loading followed by $0.9 \mathrm{~s}$ rest period and a haversine load waveform is used. This test protocol has serious limitation and these are due to the loading conditions applied and the post-processing procedure followed for flow number determination. In this investigation, three changes were made in the existing flow number protocol. The first one was in the load waveform. A trapezoidal waveform was used instead of the haversine load waveform. The second change was related to loading conditions. Different combinations of confinement and deviatoric loading were applied and the final choice was made based on the resulting three stage creep curve. The third change was related to post-processing method and a Francken model to capture the complete three stages of deformation was used. A BC mix with mid-gradation following MoRTH (Specifications for roads and bridge works. Indian Roads Congress, New Delhi 2013) guidelines was used with VG30 and CRMB60 binder. PReSBOX shear compactor was used for making cylindrical samples of $94 \mathrm{~mm}$ diameter and $150 \mathrm{~mm}$ height. The samples were cast with a target air voids of $6 \%$. All the testing was carried out at 50 and $60{ }^{\circ} \mathrm{C}$. Different confinement conditions ranging from 50 to $200 \mathrm{kPa}$ were used with the deviatoric loading ranging from 200 to $600 \mathrm{kPa}$. The influence of modified binder was clearly seen in the development of three stage curve. The collected data was
\end{abstract}

J. Murali Krishnan jmk@iitm.ac.in

1 Department of Civil Engineering, Indian Institute of Technology Madras, Chennai 600036, India post-processed using Francken model and the flow number was determined. This flow number was bench marked with the existing flow number protocol and it was seen that there were gross discrepancies.

Keywords Flow number - Three stage creep curve . Confinement pressure $\cdot$ Viscoelasticity $\cdot$ Rutting $\cdot$ Francken model

\section{Introduction}

One of the predominant modes of failure in bituminous pavement is rutting. It manifests in the form of longitudinal depression in the wheel path of the vehicle. Repeated action of wheel load in the presence of high temperature leads to accelerated rutting of the pavement. The creep and recovery tests have been traditionally used to quantify the rutting susceptibility of the mixtures [1]. As part of the NCHRP project 9-19, an asphalt mixture performance tester (AMPT) was designed and three test protocols have been proposed. These are dynamic modulus, flow time and flow number tests. While dynamic modulus is used as an input parameter in the mechanistic-empirical pavement design guidelines, flow time and flow number are performance tests specifically designed for the purpose of characterizing the rut resistance of bituminous mixtures [2]. Flow time is a creep test without any recovery whereas flow number is a repeated creep and recovery test with a fixed rest period. It is observed that the repeated creep and recovery test have higher probability in predicting the rutting characteristics of hot mix asphalt [3].

The existing protocol for flow number subjects the material to haversine loading of $0.1 \mathrm{~s}$ followed by $0.9 \mathrm{~s}$ of rest period with $600 \mathrm{kPa}$ deviatoric loading under unconfined condition [4]. In such loading, the material is not 
allowed to creep and reach a steady state and also the rest period given may not be sufficient enough to reach a steady state of residual strain. Hence the residual strain exhibited may not be the true residual strain, rather a strain at a transient stage. The specimens subjected to higher deviatoric stresses in creep and recovery tests are most likely to fail and hence the rutting characteristics of the bituminous mixtures cannot be captured effectively. Also, it should be pointed out that the AASHTO protocol as implemented in AMPT collects only the irrecoverable deformation at the end of each cycle.

Kim and Coree [5], have clearly pointed out that for stress levels above $200 \mathrm{kPa}$ in unconfined mode, the sample can fail without a distinct three stage curve. Also if one uses deviatoric stresses less than $200 \mathrm{kPa}$ for modified bituminous mixtures, one cannot map the tertiary creep and hence it is required to conduct the tests at deviatoric stress levels of $500 \mathrm{kPa}$ [6]. Many researchers (Bhasin et al. [7]; Archilla et al. [8]; Biligiri et al. [9]; Zhang and Pie [10]; Modhaddam et at. [11]) have performed flow number experiments on bituminous mixtures with haversine loading of $0.1 \mathrm{~s}$ loading period continued by a rest period of $0.9 \mathrm{~s}$. Hajj et al. [12] simulated the stress in the pavement due to traffic loading for determination of loading time duration and magnitude of deviatoric loading for creep and recovery test. This study concluded that the loading pulse of $0.1 \mathrm{~s}$ is insufficient to capture the real time traffic loading condition. Recently, Roy et al. [13] proposed a trapezoidal waveform of $0.4 \mathrm{~s}$ loading period and $0.6 \mathrm{~s}$ rest period to study the creep behaviour of the bituminous material.

The pavement experiences confinement pressure under repeated wheel load. In order to mimic this field condition, the laboratory experiments should be carried out under confinement conditions at those appropriate temperatures. Witczak et al. [14] recommended a confinement of 35-207 kPa. Later, Bonaquist et al. [15] revised the confinement value as $69 \mathrm{kPa}$ based on which the provisional AASHTO standard has been drafted. Even though the flow number test can be run without confinement as per AASHTO provisional standard [4], it is understood that such tests should be conducted under confinement so that the test conditions can be closer to reality [12]. Another important issue is the post processing of creep and recovery data to obtain the flow number. There are various post processing methods proposed to calculate the flow number from creep and recovery data. Since flow number corresponds to the minimum strain rate during the secondary stage, it is understood that different numerical differentiation procedure can lead to different flow number. As of now, no constitutive model exists to capture the stress-strain response of the material for a flow number experiment for all the cycles and only empirical models such as the Francken model is used to capture the complete three stages of deformation [16].
It is necessary that the material should exhibit a three stage creep curve so that the flow number determined is precisely at the bifurcation point of secondary and tertiary stages. Such concerns gain significance when modified binders are used in pavement application. Due to the superior performance characteristics (immediate recovery of strain and less irrecoverable strain) of such mixtures the creep and recovery test protocols may need a considerable relook. In this paper, the repeated creep and recovery test for bituminous mixture was conducted for extended loading and recovery time with the confinement condition and the results were compared with the standard recommended haversine loading. The bituminous mixture produced using VG30 and CRMB 60 binder were used for the study.

\section{Experimental Design}

\section{Materials and Sample Fabrication}

Mid-aggregate gradation of BC-grade II with nominal maximum size of $13 \mathrm{~mm}$ from MoRTH [17] was chosen. The binder content of $5 \%$ by mass of total mixture was chosen to cast the samples with $6 \pm 0.5 \%$ air voids using a PReSBOX shear compactor. The bituminous mixture samples were produced using conventional VG30 and CRMB 60 binders. While VG30 is an unmodified binder meeting IS73-2013, CRMB60 is a crumb rubber modified binder meeting the requirements as per IS:15462-2004. The PReSBOX shear compactor was used so as to get the uniform air void distribution throughout the cross section of a sample. The mixing temperature of unmodified and modified binder was taken as $150 \pm 0.5$ and $170 \pm 0.5^{\circ} \mathrm{C}$ respectively [18]. An automatic bituminous mixer machine was used for the proper mixing of aggregate with bitumen. The bituminous mixture was conditioned for $4 \mathrm{~h} \pm 5 \mathrm{~min}$ at $135 \pm 0.3$ and $155 \pm 0.3{ }^{\circ} \mathrm{C}$ for unmodified and modified binder respectively in order to simulate the effect of mixture aging and binder absorption during the pre-compaction phase in the field. The compaction temperature was taken as $150 \pm 0.5$ and $170 \pm 0.5^{\circ} \mathrm{C}$ for unmodified and modified binders respectively [18]. The compaction was carried out by the combined effect of static vertical force and cyclic shear force (up to $50 \mathrm{kN}$ ). The specimen size of $450 \mathrm{~mm}$ long, $150 \mathrm{~mm}$ width and 145-180 mm depth obtained from PReSBOX shear compactor was then cored to get three cylindrical samples of $100 \mathrm{~mm}$ diameter and $150 \mathrm{~mm}$ height.

Table 1 shows the test matrix associated with the experiments carried out in this study. As can be seen, an unmodified binder (VG30) and a modified binder (CRMB60) were used in sample fabrication. Each of the samples were first tested in the existing flow number test method (haversine loading of $0.1 \mathrm{~s}$ loading followed by 0.9 s rest period with deviatoric load of 
Table 1 Test matrix

\begin{tabular}{ll}
\hline Mix type & BC-VG30, BC-CRMB60 \\
\hline Temperature $\left({ }^{\circ} \mathrm{C}\right)$ & 50,60 \\
Axial stress $(\mathrm{kPa})$ & 600,200 \\
$\begin{array}{c}\text { Confinement } \\
\text { pressure, } \mathrm{kPa}\end{array}$ & $0,75,200$ \\
Test loading & $\begin{array}{c}\text { Haversine loading }(0.1 \mathrm{~s}, 0.9 \mathrm{~s}) \text {; Trapezoidal } \\
\text { loading }(1 \mathrm{~s}, 2 \mathrm{~s})\end{array}$ \\
Test protocol & $\begin{array}{c}\text { Existing flow number protocol, Modified flow } \\
\text { number protocol and New creep and recovery } \\
\text { protocol }\end{array}$ \\
$\begin{array}{c}\text { Prancken model } \\
\text { algorithm }\end{array}$ & \\
\hline
\end{tabular}

$600 \mathrm{kPa}$ magnitude). Since the existing flow number protocol can give only the irrecoverable deformation at the end of each cycle, a new test method was designed keeping the haversine load waveform. However, the samples were subjected to $200 \mathrm{kPa}$ deviatoric loading without and with confinement loading $(200 \mathrm{kPa})$. Also, in this protocol all the deformation data was acquired. In the third protocol, a trapezoidal wave form was applied. As the main aim is to capture the three stage creep curve, different trials have to be carried out involving considerable experimentation. It was found that $600 \mathrm{kPa}$ deviatoric loading with $75 \mathrm{kPa}$ confinement condition could bring out the essential features of the three stage creep curve model.

\section{Flow Number Test 1 (Existing Flow Number Protocol)}

In this experiment, a haversine waveform of $0.1 \mathrm{~s}$ loading is given followed by $0.9 \mathrm{~s}$ rest period. An axial load of $600 \mathrm{kPa}$ is stipulated [4]. Creep and recovery test results can be presented in terms of cumulative irrecoverable strain versus number of loading cycles. If the test is carried out for a sufficiently longer period of time, this curve can consist of three stages. In the primary stage, the irrecoverable strain value increases at a decreasing rate, in the secondary stage the irrecoverable strain increases at a constant rate and in the tertiary stage the irrecoverable strain rate increases at an increasing rate. This test data is analyzed and the number of cycle corresponding to the initiation of tertiary stage is taken as the flow number value [14].

Figure 1 shows the irrecoverable strain as a function of number of cycles at 50 and $60{ }^{\circ} \mathrm{C}$ for the bituminous mixture with VG30 (Fig. 1a) and CRMB60 (Fig. 1b) binder when tested using standard flow number protocol. The effect of temperature on the response of the bituminous mixtures was as expected. At higher temperature, the irrecoverable strain was higher than at lower temperature. The trend was same for all samples irrespective of the type of binder.

The flow number cycle corresponding to the initiation of the tertiary stage was calculated from these creep curve using Francken model [16]. According to Francken, the creep of bituminous mixture can exhibit two types of behaviour, one is the creep curve with parabolic behaviour that is represented by $\varepsilon_{p}(t)=a t^{b}$ and another with parabolic and exponential behavior that is represented by $\varepsilon_{p}(t)=a t^{b}+c\left[e^{d t}-1\right]$. Here, $\varepsilon_{p}$ represents irrecoverable strain, $t$ represents the number of cycles and $a, b, c$ and $d$ are the model parameters. Among all model parameters, the existence of exponential behavior which indicates tertiary stage in the creep curve is represented by parameters $c$ and $d$. For this study, the irrecoverable strain as a function of number of cycles in Fig. 1 was fitted to Francken equation and the constants $a, b, c$ and $d$ were determined. The second derivative of the Francken equation was

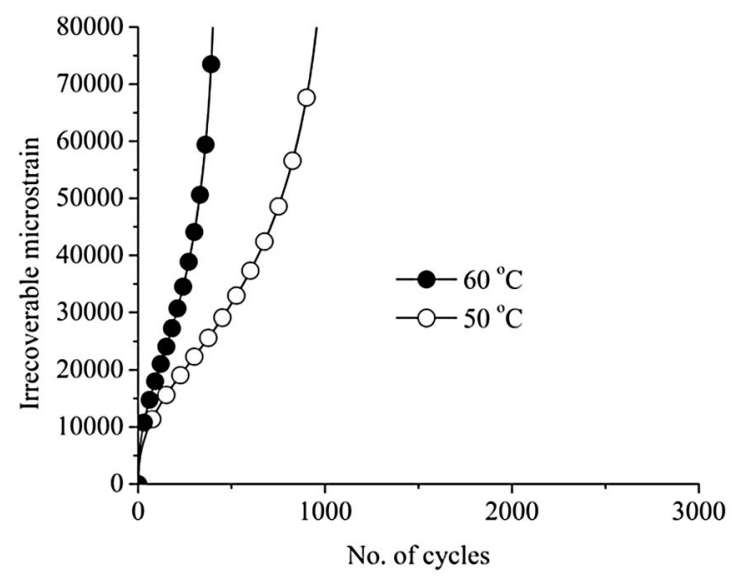

(a)

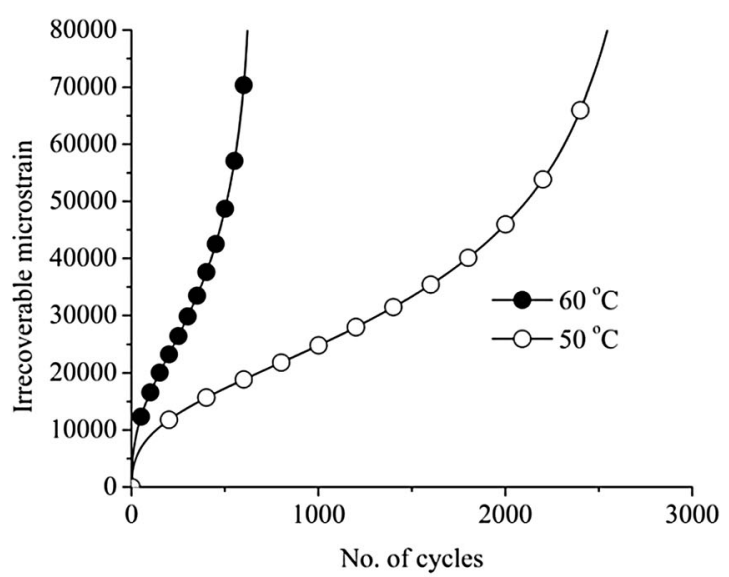

(b)

Fig. 1 Creep curve for existing flow number protocol. a VG30, b CRMB60 
Table 2 Flow number valuesregular protocol (existing flow number protocol)

\begin{tabular}{llr}
\hline Mix & $50{ }^{\circ} \mathrm{C}$ & $60{ }^{\circ} \mathrm{C}$ \\
\hline VG30 & 304 & 74 \\
CRMB 60 & 617 & 158 \\
\hline
\end{tabular}

obtained and the number of cycles corresponding to slope change in the derivative curve was identified as the flow number. The flow number obtained for each sample is tabulated (Table 2).

As can be seen, the existing flow number tests with $600 \mathrm{kPa}$ deviatoric stress subjected the material to higher levels of stress and led to an immediate failure of the material without generating a prolonged secondary stage. Taking into account this issue, the flow number protocol was modified and this is now discussed in the next section.

\section{Flow Number Test 2 (Modified Flow Number Test Protocol)}

In order to capture the rutting behaviour of the bituminous materials, the existing flow number protocol was customized with $200 \mathrm{kPa}$ deviatoric stress with data captured for complete loading, unloading period and this new protocol is named as 'modified flow number protocol' in this paper. UTS019 [19] was the test software used to carry out this modified flow number tests. A haversine load form of $0.1 \mathrm{~s}$ loading period followed by a rest period of $0.9 \mathrm{~s}$ was applied for 20,000 cycles or till a maximum actuator displacement of $15 \mathrm{~mm}$. The material was subjected to $200 \mathrm{kPa}$ of deviatoric loading under zero confinement condition and $200 \mathrm{kPa}$ confinement conditions.

Figure 2 shows the irrecoverable strain of VG30 at 50 and $60{ }^{\circ} \mathrm{C}$ under unconfined and confined conditions. Similar results were obtained for CRMB60 mix and they are not shown here for brevity. Confinement pressure plays a vital

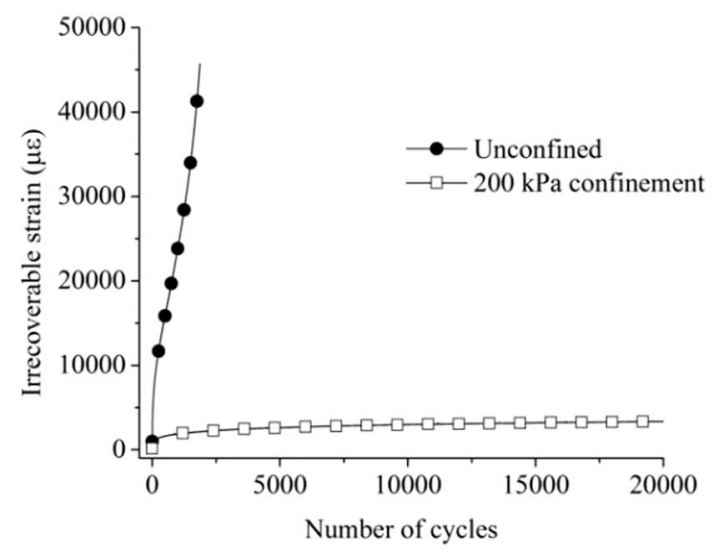

(a) role in the response of the bituminous mixtures in creep and recovery tests. It was observed that the strains are very high for those samples tested in unconfined condition. The test under $200 \mathrm{kPa}$ confinement effectively stiffened the material and hence the obtained strains were very less compared to that tested at unconfined condition. The test carried out under confinement did not result in a three stage creep curve.

The flow number values obtained from different binder test data were found out using Francken model approach and they are given in Table 3.

\section{Flow Number Test 3 (New Creep and Recovery Test)}

This test protocol consists of repeated trapezoidal waveform loading with $1 \mathrm{~s}$ loading time and $2 \mathrm{~s}$ recovery periods. The deviatoric stress was increased at a rate of $1860 \mathrm{kPa} / \mathrm{s}$, kept constant for $0.8 \mathrm{~s}$ and then unloaded at the same rate of loading (Fig. 3).

The loading cycles followed by the rest period was applied for 20,000 cycles or till a maximum actuator displacement of $15 \mathrm{~mm}$. The trapezoidal waveforms used in new creep and recovery tests were developed in UTS 019, associated with the AMPT of IPC global [19]. The desired shape of the loading wave was obtained through the fine tuning of the load form, by changing the Proportional, Integral and Derivative (PID) controller. The waveform corresponding to different PID values was compared with the theoretical wave form and its variation from the theoretical waveform was measured using Root Mean Square (RMSE) value. Since it was not clear what combinations of confinement and deviatoric loading can give a three stage curve, different combinations were tried (Table 4).

Figure 4 shows the total strains corresponding to the first three trial combinations carried out on CRMB bituminous mixtures at $60{ }^{\circ} \mathrm{C}$. It is seen that the material did

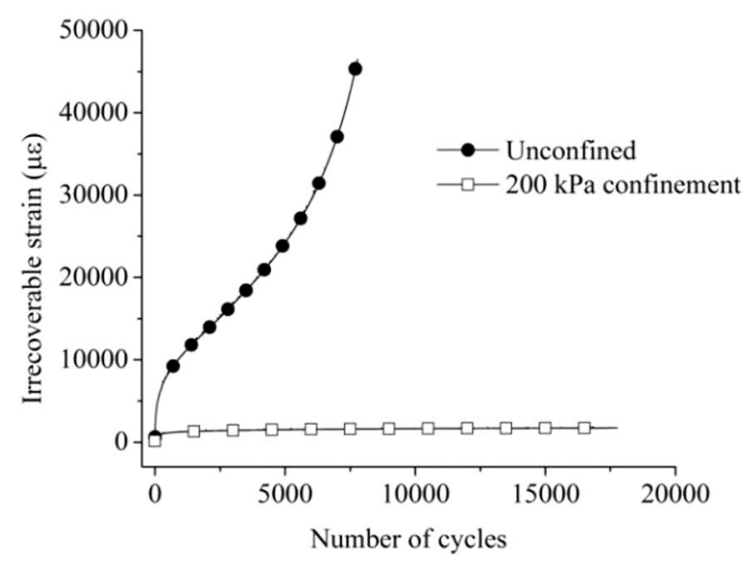

(b)

Fig. 2 Creep curve of VG30 bituminous mixture (Modified flow number protocol). a $50{ }^{\circ} \mathrm{C}, \mathbf{b} 60{ }^{\circ} \mathrm{C}$ 
Table 3 Flow number valuesmodified protocol

\begin{tabular}{|c|c|c|c|c|}
\hline \multirow[t]{2}{*}{ Mix } & \multicolumn{2}{|c|}{$0 \mathrm{kPa}$ Confinement pressure } & \multicolumn{2}{|c|}{$200 \mathrm{kPa}$ Confinement pressure } \\
\hline & $50^{\circ} \mathrm{C}$ & $60{ }^{\circ} \mathrm{C}$ & $50{ }^{\circ} \mathrm{C}$ & $60{ }^{\circ} \mathrm{C}$ \\
\hline VG30 & 638 & 278 & $20,000+$ & $20,000+$ \\
\hline CRMB 60 & 2475 & 1160 & $20,000+$ & $20,000+$ \\
\hline
\end{tabular}

Fig. 3 Schematic representation of modified flow number protocol

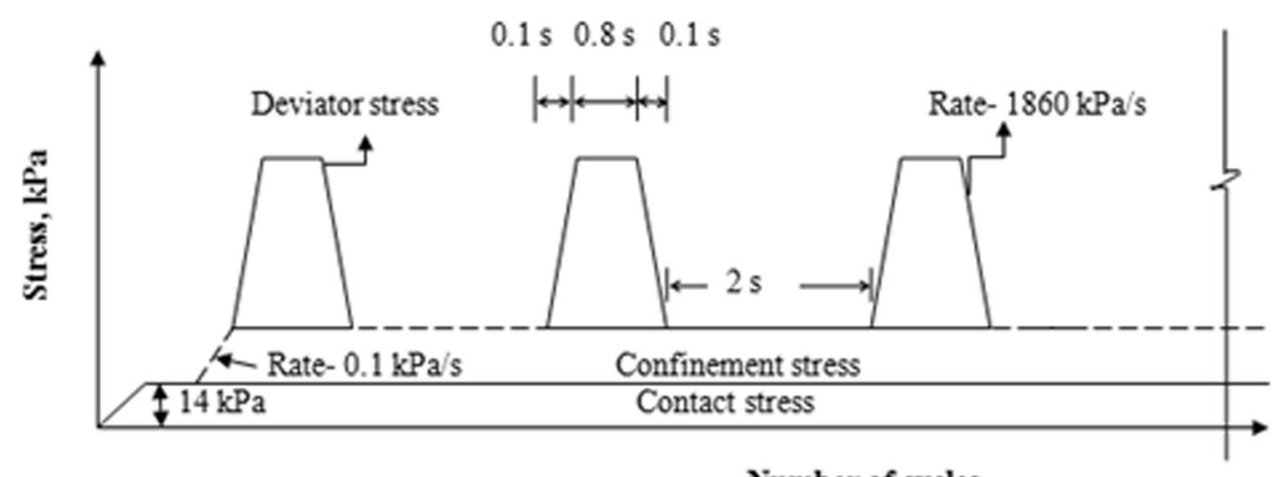

Number of cycles
Table 4 Various combinations of deviatoric stress and confinement pressure

\begin{tabular}{lllllrrr}
\hline Loading & Trial 1 & Trial 2 & Trial 3 & Trial 4 & Trial 5 & Trial 6 & Trial 7 \\
\hline Deviatoric stress $(\mathrm{kPa})$ & 400 & 400 & 300 & 600 & 600 & 600 & 600 \\
Confinement pressure $(\mathrm{kPa})$ & 200 & 100 & 100 & 100 & 0 & 50 & 75 \\
\hline
\end{tabular}

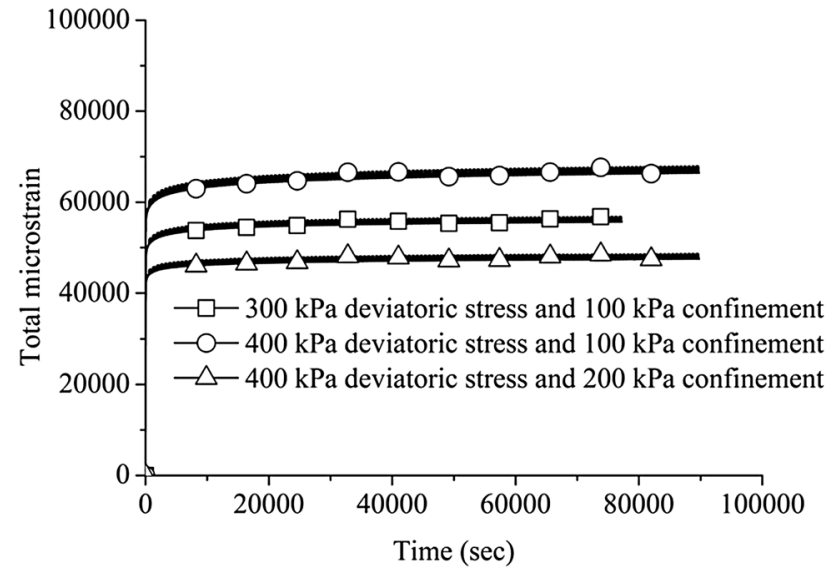

Fig. 4 Creep curve for $\mathrm{CRMB}$ mixture at $60{ }^{\circ} \mathrm{C}$ - trial set 1

not exhibit the tertiary stage within the loading period. The deviatoric stress was then increased to $600 \mathrm{kPa}$ to make it comparable with the loading stress of regular protocol. The confinement pressure was varied from 0 to $100 \mathrm{kPa}$, to obtain a three stage curve (Fig. 5). As can be seen, the combination of deviatoric stress of $600 \mathrm{kPa}$ and confinement pressure of $75 \mathrm{kPa}$ resulted in a classical three stage creep curve (Fig. 6).

These selected combinations of loading were used to test VG30 and CRMB bituminous mixtures at 50 and $60{ }^{\circ} \mathrm{C}$.

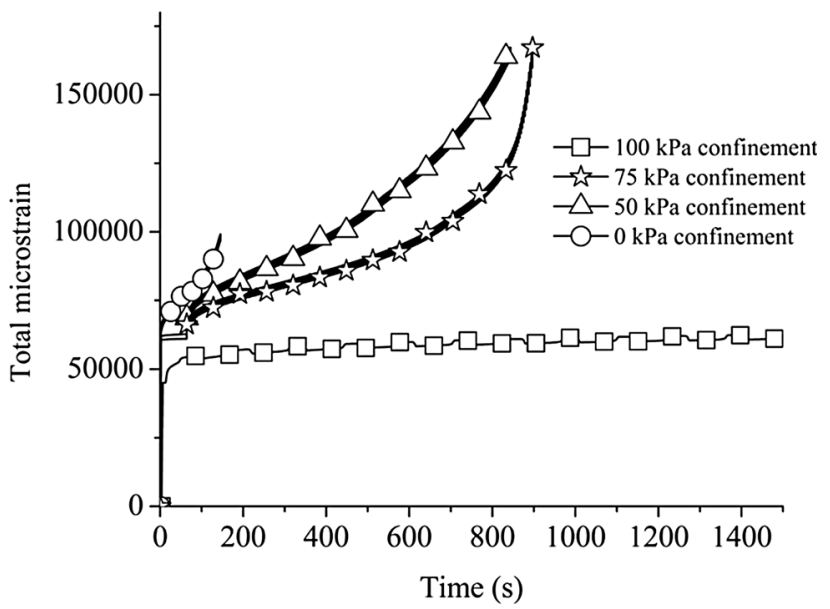

Fig. 5 Creep curve for CRMB mixture at $60{ }^{\circ} \mathrm{C}$ - trial set 2

The experiments at $50{ }^{\circ} \mathrm{C}$ showed contrasting trends and are currently being repeated.

The data was fitted using Francken model for the determination of flow number values. Table 5 shows the parameters of Francken model and flow number values for the creep and recovery tests at $600 \mathrm{kPa}$ deviatoric stress and $75 \mathrm{kPa}$ confinement at the temperature of $60^{\circ} \mathrm{C}$. Figure 7 shows the response of irrecoverable strain with respect to number of cycles for CRMB 60 bituminous 
mixture sample tested at $60{ }^{\circ} \mathrm{C}$ and Fig. 8 shows the same for VG30 binder. These figures are shown here to emphasize the clear and prolonged development of secondary stage using the new test protocol. The rate of

Table 5 Francken model parameters and flow number values at $60{ }^{\circ} \mathrm{C}$ with new creep and recovery test at $600 \mathrm{kPa}$ deviatoric stress and $75 \mathrm{kPa}$ confinement

\begin{tabular}{lllllll}
\hline $\begin{array}{l}\text { Bituminous } \\
\text { type }\end{array}$ & $a$ & $b$ & $c$ & $d$ & $R^{2}$ & $\begin{array}{l}\text { Flow } \\
\text { number }\end{array}$ \\
\hline VG30 & 3358 & 0.594 & 0.091 & 0.209 & 0.995 & 35 \\
CRMB & 2790 & 0.463 & 33.600 & 0.026 & 0.998 & 70 \\
\hline
\end{tabular}

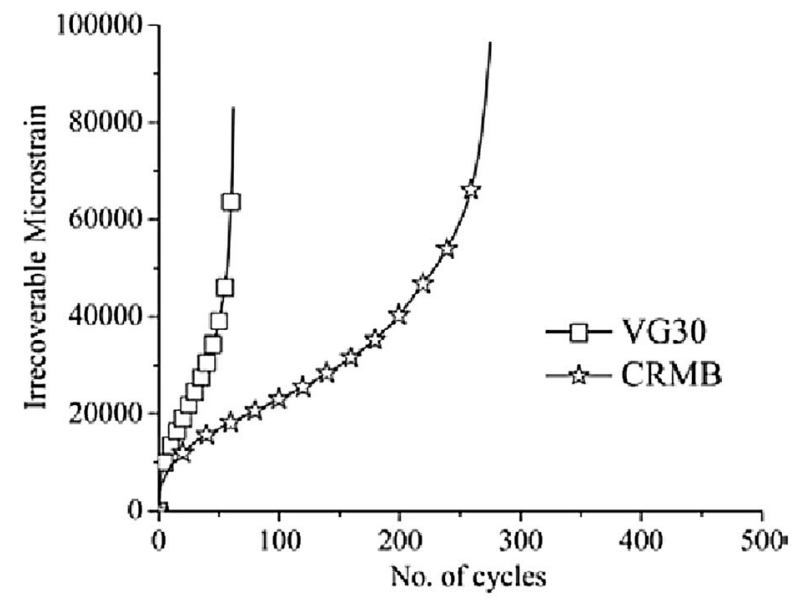

(a) change of strain value continuously decreased and at a particular cycle number it started increasing.

The CRMB60 mixes exhibited higher flow number value when compared to conventional VG30 mixtures for all the test protocols. It should be also pointed out that one should not compare the absolute value of the flow number obtained from different flow number protocols. For instance, in the trapezoidal loading, the cycle length is $3 \mathrm{~s}$ whereas for all the other test protocols, it is only $1 \mathrm{~s}$. While it is well known that CRMB60 is expected to show better rut resistance, the quantification of the same using different protocols shows different scales of improved performance. Also, the manner in which the secondary stage creep curve

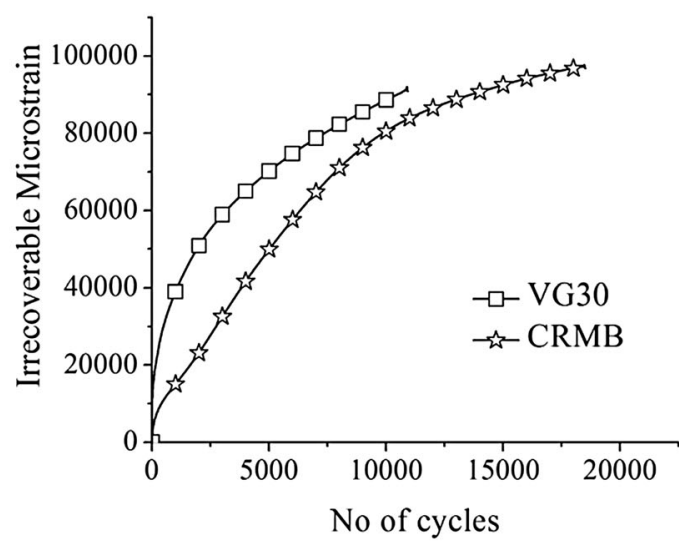

(b)

Fig. 6 Creep curve for $600 \mathrm{kPa}$ deviatoric stress and $75 \mathrm{kPa}$ confinement pressure. a $60{ }^{\circ} \mathrm{C}, \mathrm{b} 50{ }^{\circ} \mathrm{C}$

Fig. 7 Francken modelCRMB at $60{ }^{\circ} \mathrm{C}$

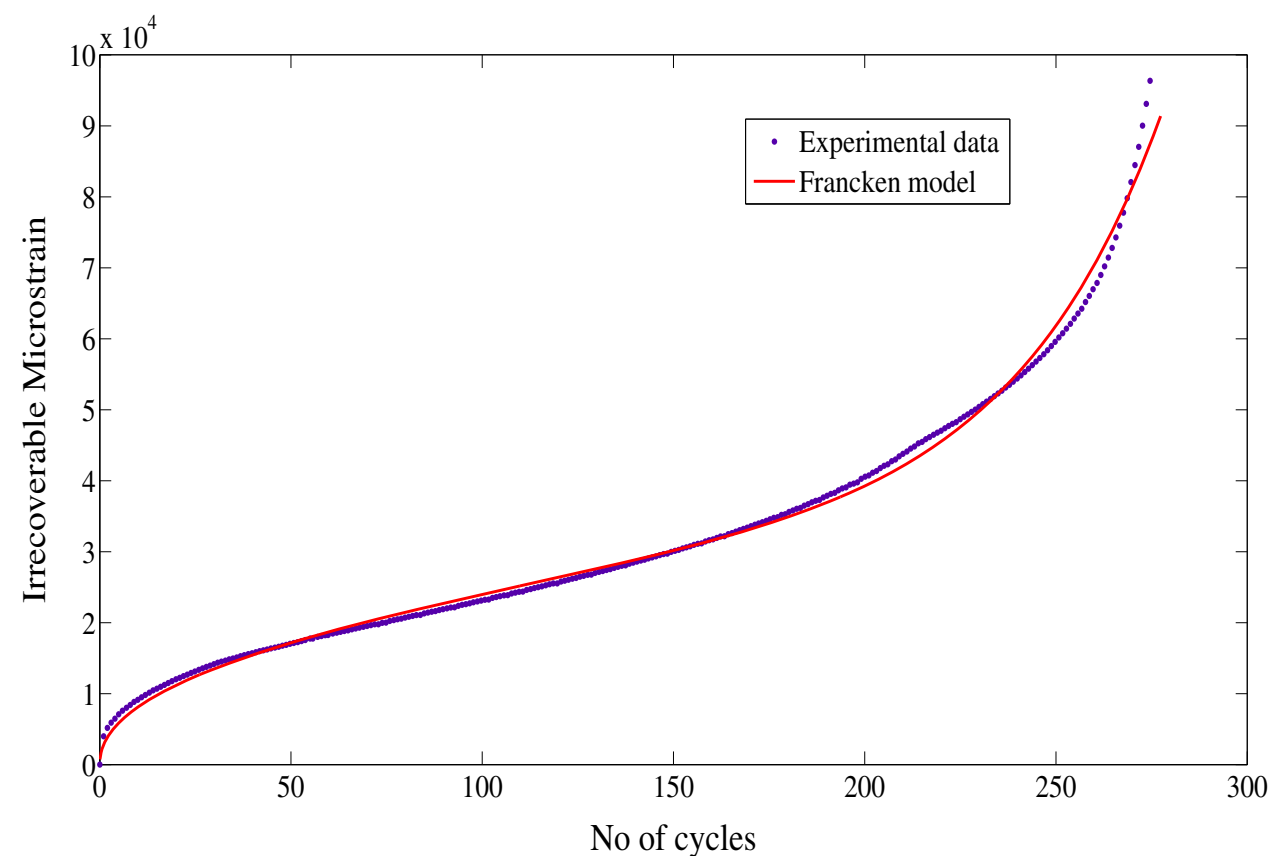


Fig. 8 Francken model-VG 30 at $60{ }^{\circ} \mathrm{C}$

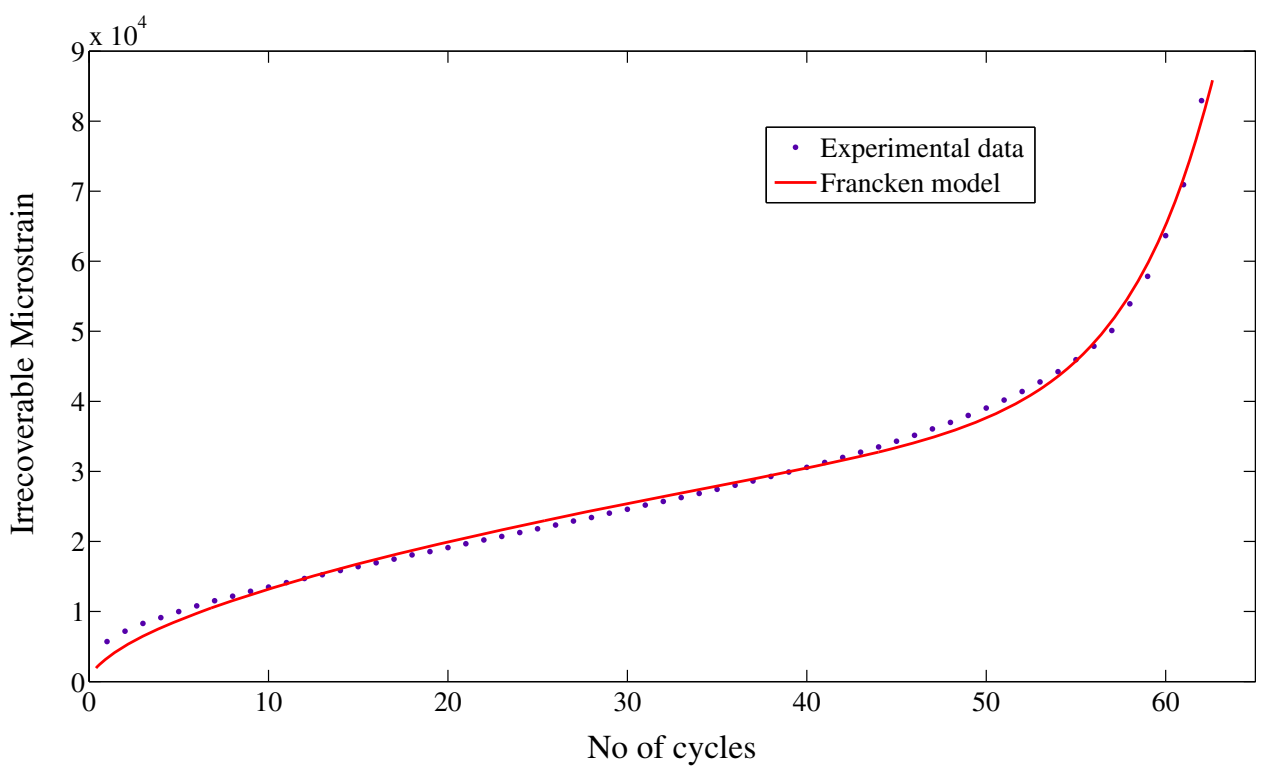

can be used to represent the rut distress transfer functions within the context of M-E PDG can be different.

\section{Conclusions}

Rutting is the most common failure that occurs in the bituminous pavement. In the current mechanistic empirical method of pavement design approach, the rutting in the bituminous mixture is characterized using recoverable strain and irrecoverable strain. The irrecoverable and recoverable strain in the bituminous mixture can be obtained using repeated creep and recovery test. The three stage creep curve that characterizes the irrecoverable deformation could be used to predict the rutting response of the mixture. If one uses the current flow number test protocol to obtain the creep curve of the bituminous mixture, it was observed that the response transitions from primary to tertiary stage without an appreciable secondary stage. It was seen that the confinement pressure plays a vital role in the response of the bituminous mixtures in creep and recovery tests. It is necessary to systematically compute the expected confinement in the field and use it to quantify the rut resistance of the mixture. However, such confinement can increase the total duration of testing and this is an area in which considerable work is required.

Acknowledgments This research work was supported by Department of Science and Technology, Govt. of India vide Grant Number: DST/TSG/STS/2011/46. This support is gratefully acknowledged. The authors acknowledge the opportunity to present the research work that forms the basis of this article at the 3rd Conference of the Transportation Research Group of India held at Kolkata (India) from 17 to 20 December, 2015.

\section{References}

1. Bolk HJNA, Van der Loo PJ (1978) The creep test: A routine method for the design of stable asphalt mixes, Eurobitume Seminar: The challenge of the future for asphalt roads, London, pp 89-98

2. Mechanistic-Empirical Pavement Design Guide (2004) National Cooperative Highway Research Program. Transportation Research Board, National Research Council, Washington DC

3. Brown ER, Foo KY (1994) Comparison of unconfined and confined creep tests for hot mix asphalt. J Mater Civ Eng 6:307-326

4. AASHTO (2013) TP-79., Standard method of test for determining the dynamic modulus and flow number for hot mix asphalt (HMA) using the Asphalt mixture performance tester (AMPT). American Association of State Highway and Transportation Officials, Washington DC

5. Kim S, Coree BJ (2005) Evaluation of hot mix asphalt moisture sensitivity using the Nottingham asphalt test equipment. Rep. No. IHRB Project TR-483, Dept. of Civil, Construction, and Environmental Engineering, Iowa State Univ., Ames, Iowa

6. Tapkin S, Uşar U, Tuncan A, Tuncan M (2009) Repeated creep behavior of polypropylene fiber-reinforced Bituminous mixtures. J Transp Eng 135(4):240-249

7. Bhasin A, Button JM, Chowdhury A, Masad E (2006) Selection of optimum gravel aggregate size to resist permanent deformation in hot mix asphalt, 86th Annual Meeting, Transportation Research Board, Washington DC

8. Archilla AR, Diaz LG, Carpenter SH (2007) Proposed method to determine the flow number from laboratory axial repeated loading tests in bituminous mixtures. J Transp Eng 133(11):610-617

9. Biligiri K, Kaloush KE, Mamlouk M, Witczak MW (2001) Rational modeling of tertiary flow for asphalt mixtures. J Transp Res Board 2001:63-72

10. Zhang J, Pei J (2011) Research on flow number of asphalt mixture under high temperature and heavy load. Road Mater New Innov Pav Eng. doi:10.1061/47634(413)8

11. Moghaddam TB, Soltani M, Karim MR (2014) Evaluation of permanent deformation characteristics of unmodified and Polyethylene Terephthalate modified asphalt mixtures using dynamic creep test. Mater Des 53:317-324 
12. Hajj EY, Ulloa A, Siddharthan R, Sebaaly PE (2010) Estimation of stress conditions for the flow number simple performance test, Journal of the Transportation Research Board, No. 2181, Transportation Research Board of the National Academies, Washington, DC, pp 67-78

13. Roy N, Veeraragavan A, Krishnan JM (2016) Influence of confinement pressure and air voids on the repeated creep and recovery of asphalt concrete mixtures. Int $\mathrm{J}$ Pavement Eng 17(2):133-147

14. Witczak MW, Kaloush K, Pellinen T, El-Basyouny M, Quintus HV (2002) NCHRP report 465: Simple performance tests for superpave mix design, National Cooperative Highway Research Program, Transportation Research Board, Washington, DC

15. Bonaquist $R$ (2011) Precision of the dynamic modulus and flow number tests conducted with the asphalt mixture performance tester. National Cooperative Highway Research Program, Transportation Research Board, Washington, DC

16. Francken L (1977) Pavement deformation law of bituminous road mixes in repeated load triaxial compression. Fourth international conference on the structural design of asphalt pavements, University of Michigan, Ann Arbor, pp 483-496

17. MoRTH (2013) Specifications for roads and bridge works. Indian Roads Congress, New Delhi

18. AASHTO (2006) R-30., Standard practice for mixture conditioning of Hot Mix Asphalt. American Association of State Highway and Transportation Officials, Washington, DC

19. IPC Global (2006) Simple performance tester-technical reference manual. IPC Global, Victoria 